\title{
Microstructure and permeability in the near-surface firn near a potential US deep-drilling site in West Antarctica
}

\author{
Ursula K. RICK, ${ }^{1}$ Mary R. ALBERT ${ }^{1,2}$ \\ ${ }^{1}$ Thayer School of Engineering, Dartmouth College, Hanover, NH 03755-8000, USA \\ E-mail: ursula.rick@colorado.edu \\ ${ }^{2}$ US Army Cold Regions Research and Engineering Laboratory, 72 Lyme Road, Hanover, NH 03755-1290, USA
}

\begin{abstract}
The microstructure of snow and firn controls the transport of chemical species from the atmosphere into and out of the underlying firn. Permeability and thick-section microstructure measurements have been made from snow-pit and firn-core samples retrieved near the proposed deepdrilling site for the inland West Antarctic ice sheet. Measurements in past investigations of polar firn show that the permeability of the snow gradually increases with depth into the core to about $2 \mathrm{~m}$, then decreases. In this core, there is a second maximum in permeability at approximately $12 \mathrm{~m}$ that is likely due to changes in meteorological conditions at the site. Either lower temperatures or higher accumulation rates in the most recent three to four decades could cause the changes in microstructure and permeability in this core. We suggest that climate shifts may alter gas records ultimately preserved in the ice because of the local climate's effect on the permeability profile.
\end{abstract}

\section{INTRODUCTION}

Historically, ice-core interpretation has been done under the assumption that the isotopes and chemistry in the ice core represent atmospheric conditions at that site when that ice was in the form of snow crystals at the surface. The importance of air-snow transfer processes has now become apparent, as they may change the concentrations of chemical species in the surface snow before it becomes part of the deeper ice (Gjessing, 1977; Cunningham and Waddington, 1993). By understanding the processes of change, we will be able to interpret signals in the ice core more accurately, leading to a better understanding of paleoclimate. Increased understanding of the nature of the snow and firn and the transport properties allows increased understanding and modeling of greenhouse and other important trace gases (Albert and others, 2002).

Diffusion and ventilation cause microstructure and chemistry changes in the near-surface firn. Diffusion is caused by thermal and chemical gradients in the firn and can occur in the firn air space down to pore close-off, where only diffusion through ice remains. However, diffusion is slow and cannot explain all of the reactive chemical-species transport found in the near-surface firn (Albert, 1996). Ventilation is a result of pressure gradients at the surface of the snow caused by surface roughness or turbulent air movement over the snow (Colbeck, 1989; Clarke and Waddington, 1991). These pressure gradients cause vertical air movement down into the snow and result in the advection of chemical species throughout the near-surface firn. Ventilation depends both on the nature of the snow and on the driving forces (Albert and others, 1996; Albert and Hawley, 2002). Ventilation may alter chemical concentrations down to several meters at some sites.

Modeling has traditionally treated the firn as a homogenous half-space, but in reality it is highly layered (Alley, 1988). Through modeling, Albert (1996) found that layering does affect the transport of air down into the firn. A lowpermeability, fine-grained, wind-packed layer at the surface would decrease airflow into the firn (compared to firn lacking a surface wind pack). In addition, she found that high-permeability layers just below the surface would enhance lateral airflow in the firn. Clearly, the snow and firn microstructure controls the permeability. In this paper, we examine the nature of the microstructure and permeability at a site near the future US deep-drilling site in West Antarctica. At this site the effects of a changing local climate on firn microstructure and permeability are evident.

\section{MEASUREMENT METHODS}

Firn cores were extracted from West Antarctica during the US International Trans-Antarctic Scientific Expedition (ITASE) 2000 field season. Site 1 of the 2000 season (named 2000-1) at $79^{\circ} 23^{\prime} \mathrm{S}, 111^{\circ} 14^{\prime} \mathrm{E}$, West Antarctica, was very near the proposed site for the inland West Antarctic ice sheet deep core site. It is particularly important, then, to examine the physical properties of the snow and firn in order to understand the air-snow exchange processes at this site. No $10 \mathrm{~m}$ borehole temperature has been taken at this site; however, the mean annual temperature was estimated to be $-31^{\circ} \mathrm{C}$ (Morse and others, 2002). The mean annual accumulation rate at this site is $22 \mathrm{~cm} \mathrm{a}^{-1}$ w.e., and at this site accumulation rates are controlled by climate-driven snow precipitation rather than by topographically driven redistribution (Kaspari and others, 2004).

Density and permeability measurements were made on the entire $16 \mathrm{~m}$ core obtained for us at the ITASE 2000-1 site. In this paper, we discuss quantitative microscopy measurements made on sections in the firn core with a homogeneous microstructure; layering effects will be the topic of future papers. The meter-long firn-core sections were cut into smaller increments depending on the layering. We identified homogeneous sections while noting the stratigraphy of the firn core on a light table in a cold room. Density was calculated by weighing individual samples, each of which was approximately $10 \mathrm{~cm}$ long, and measuring their height and diameter using calipers. Permeability of the near-surface snow and firn was measured in the field using the method and apparatus described by Albert and others (2000). Darcy's law (Equation (1)) for flow through a porous medium 


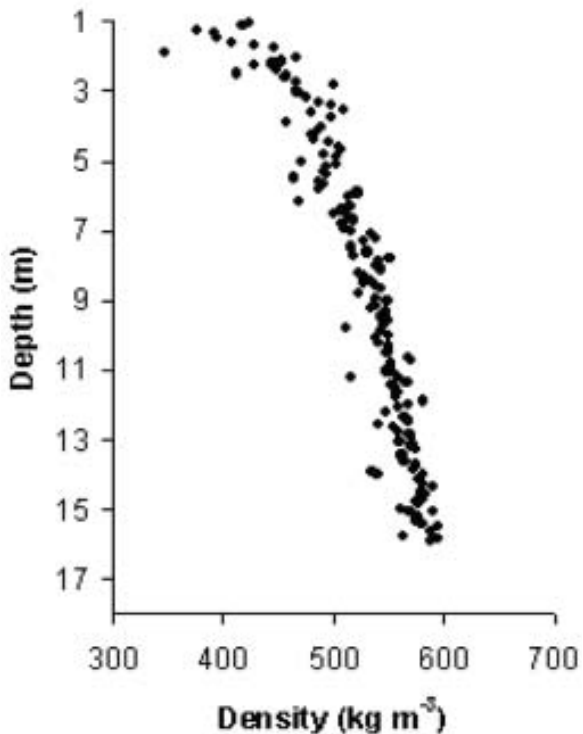

Fig. 1. Snow and firn density with depth from the surface to $16 \mathrm{~m}$ at $79^{\circ} 23^{\prime} \mathrm{S}, 111^{\circ} 14^{\prime} \mathrm{E}$, West Antarctica.

was used to calculate the permeability, $k$, of the firn. This relationship states that

$$
v=-\frac{k}{\mu} \frac{\delta P}{\delta x}
$$

where $v$ is flow rate, $\mu$ is air viscosity, $P$ is pressure, and $x$ is the direction of airflow through the sample. Permeability of the firn-core sections was measured in the cold room using a similar apparatus except that the sample holder was modified for use with firn-core sections. The sample holder consists of a pliable membrane that is inflated around the sample. This eliminates possible airflow between the sample and the holder of core samples that have irregular sides due to the coring process.

Homogeneous core sections were made into thick sections following the method in Perla (1982). Digital images were taken of each section, and the images were processed by selecting a threshold value and converting them into binary form. These images were also smoothed to eliminate tiny, anomalous groups of pixels that do not represent actually snow grains but were usually a result of glare from the sample. Quantitative microscopy statistics were calculated using Image Process Workbench (IPW) software at the US Army Cold Regions Research and Engineering Laboratory (CRREL). IPW calculates many image statistics, but the most important for this work were mean object intercept length, mean pore intercept length, and specific surface. Each of these measurements requires IPW to generate many test lines across the image. For surface calculations, it counts the number of times a boundary between snow grain and pore crosses the line; for mean grain and pore intercept lengths, it measures the average length of snow grain or pore along that line. The intercept lengths are similar to a mean diameter and are a good representation of grain- or pore size. Comparisons have been made between grain-size measurements made with a hand lens and grain-size calculated by quantitative microscopy (personal communication from R. Davis, 2003). Separate groups of 40 people examined snow grains using hand lenses. Special care was taken to measure all sizes of

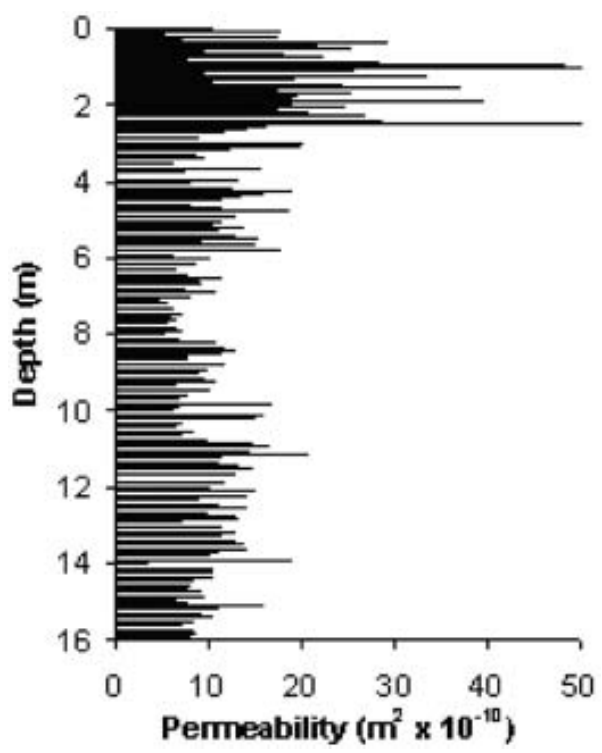

Fig. 2. Permeability profile of the top $16 \mathrm{~m}$ of the snow and firn at $79^{\circ} 23^{\prime} \mathrm{S}, 111^{\circ} 14^{\prime} \mathrm{E}$.

snow grains in each snow sample because the human eye is naturally drawn to the larger grains. It was found that the quantitative microscopy measurements usually fell within one standard deviation of the mean of the hand lens measurements. The firn was assumed to be isometric for each quantitative microscopy measurement.

\section{RESULTS}

Density gradually increases with depth in the core, as can be seen in Figure 1. Traditionally, density has been considered by glaciologists to be a rough indicator of transfer rates in the firn, but the permeability profile in Figure 2 does not follow the same profile with depth as density, confirming observations by Albert and others (2000) and Luciano and Albert (2002) that density is a poor indicator of permeability in firn. The permeability increases gradually to a maximum at about $2 \mathrm{~m}$ and then gradually decreases to about $8 \mathrm{~m}$. At approximately $8 \mathrm{~m}$, the permeability begins to increase with depth again to a depth of $12 \mathrm{~m}$, where it again decreases (Fig. 2). To the best of our knowledge, this second subsurface maximum has never been observed in permeability measurements of polar firn. Typically, the profiles previously measured have had single maxima at depths of several meters, as seen in measurements at Summit Greenland (Albert and Shultz, 2002) and at Siple Dome, Antarctica (Albert and others, 2000). In our core, the first maximum corresponds to an age of about 2.5 years and the second maximum, of lesser amplitude, occurs at an age of about 20 years (personal communication from D. Meese, 2003). As is clearly seen by comparing this permeability profile with the density profile (Fig. 1), which was obtained from the same pieces of firn core, density is not the root cause of the permeability profile of the firn. Below, we investigate the nature of the snow and firn microstructure at this site, and we discuss the metamorphic processes that brought about these changes. The measurements show that the microstructure of the firn is responsible for these changes in the permeability profile.

The quantitative microscopy measurements of 


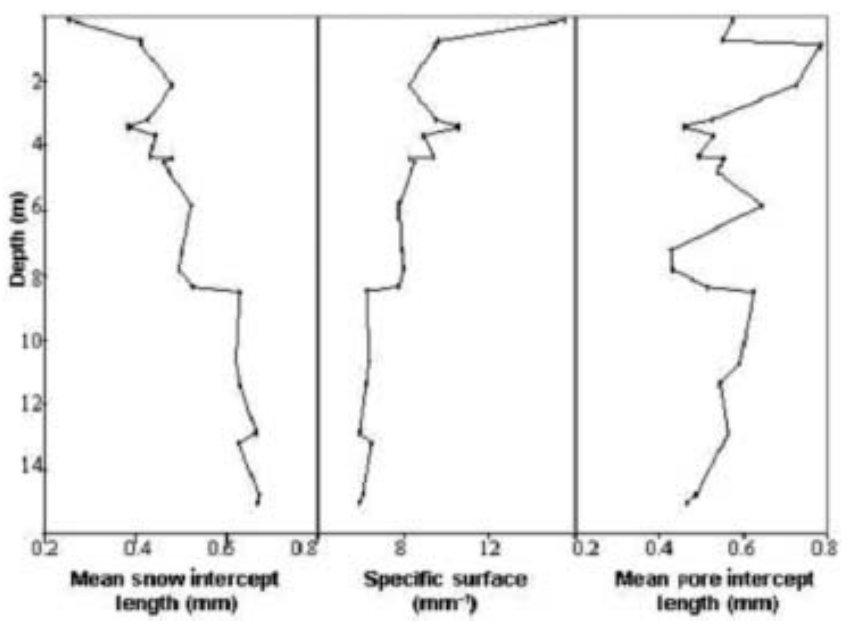

Fig. 3. Mean grain-size, mean pore size, and specific surface variations with depth in fine-grained layers at $79^{\circ} 23^{\prime} \mathrm{S}, 111^{\circ} 14^{\prime} \mathrm{E}$.

homogeneous fine-grained layers at various depths are plotted in Figure 3. These layers are each more fine-grained than other layers in close proximity, so we infer that they were probably all wind pack when they were on the surface. The mean object intercept length, or mean snow grain-size, generally increases with depth. Conversely, the specific surface decreases with depth. Both of these phenomena are due to recrystallization of the firn.

The increase in grain-size and decrease in specific surface are more rapid in the top few meters because of more severe temperature gradients induced by seasonal weather patterns. The very-near-surface firn is exposed to diurnal and seasonal temperature gradients. These are strong enough to induce rapid vapor transport, leading to the growth of the larger snow grains at the expense of the smaller grains (Colbeck, 1983). These metamorphic processes increase the mean grain-size with time (depth) and also decrease the amount of snow grain surface. The pore network expands and becomes better connected, thus increasing the permeability in the near-surface as the snow ages. It can be seen in the top two images in Figure 4 that, between the surface and $0.88 \mathrm{~m}$, the mean grain-size and mean pore sizes of the fine-grained wind pack increase rapidly, and the individual grains are not connected to one another. This leaves an open network of pores through which air can easily travel, increasing the potential for ventilation in the top several meters.

Below the top meter, the firn is exposed only to seasonal temperature gradients, which are not strong enough to drive temperature gradient metamorphism (Rick and Albert, 2004). Thus, equitemperature metamorphism or isothermal grain growth takes over as the dominant metamorphic process in the firn below $1 \mathrm{~m}$ depth. The grains continue to grow (Fig. 3), but necks are formed between them as they sinter together (Fig. 4) and become more spherical. This reduces the specific surface further and also closes off the pore network, and it makes air transport through the firn more difficult. This can be seen in Figure 2, where the permeability begins to decrease below $2 \mathrm{~m}$, and in Figure 4, where the images from the four greatest depths have necks between snow grains and fewer interconnected pores.

Below $10 \mathrm{~m}$, the firn experiences very small temperature gradients, and grain growth is classified as isothermal (Colbeck, 1983). The rate of isothermal grain growth

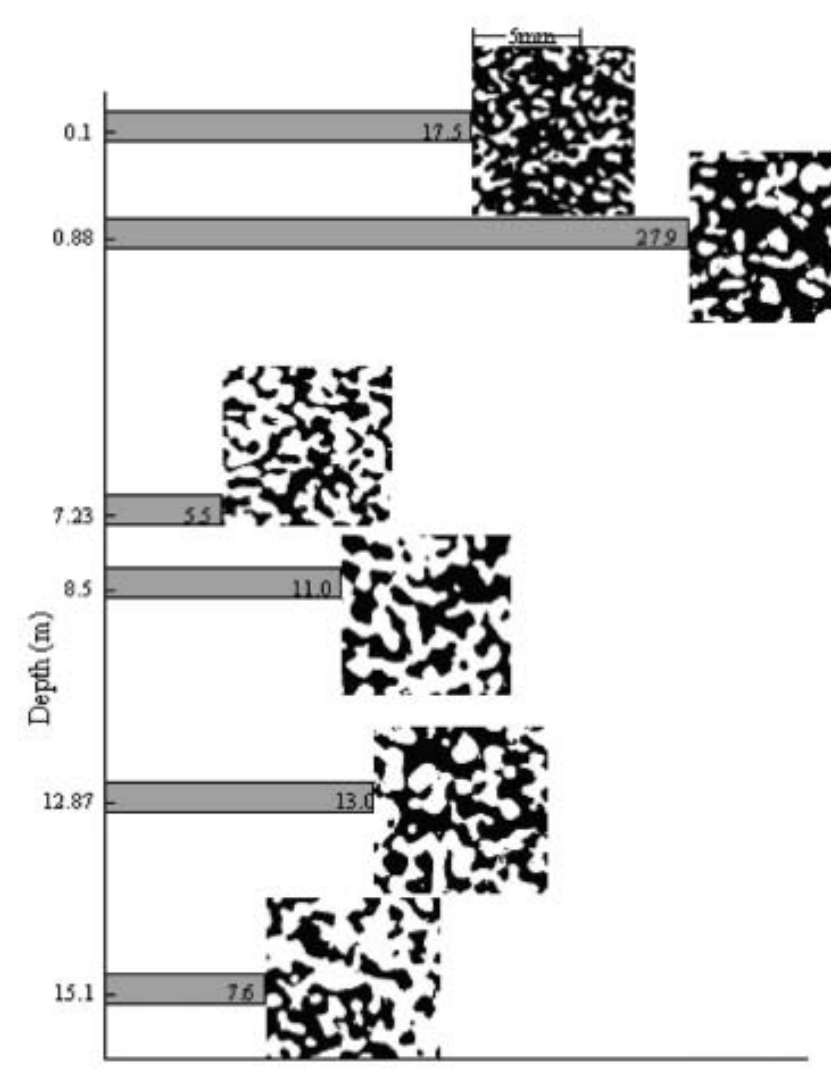

Perme ability $\left(\mathrm{m}^{2} \times 10^{-11}\right)$

Fig. 4. Digital images of fine-grained firn samples from the 2000-1 site. Images are placed according to their depth and permeability. The scale is the same for all images, and stratigraphic up is to the left. Black represents pore space and white represents snow.

depends on temperature (Gow, 1969); in warmer conditions, the grains grow faster. Although the region of firn 1-10 m deep does not experience temperature gradient metamorphism, it experiences higher temperatures during the summer. Thus, the grains would be growing faster for that part of the year. Figure 3 shows that grain growth in the region 1-10 m deep is moderate.

It is important to note the difference between the pattern of pore size change with depth and the patterns of mean grain-size and specific surface change. Figure 4 illustrates permeability changes and microstructure changes with depth on firn samples that were wind-packed snow when they were on the surface. The length of the gray bars represents the permeability of the sample from which the corresponding digital image was taken. The values on the vertical axis are the depth in the firn from which these samples were taken. We see in the images of Figure 4 that grain-size continuously increases down through the core, while pore size increases and then decreases, similar to the permeability profiles. The images indicate that the pore characteristics, rather than grain-size, control transport through the firn.

The ITASE 2000-1 firn core presents some exceptions to the usual steady decrease in permeability below about $2 \mathrm{~m}$ seen in other firn cores (Albert and others, 2000; Albert and Shultz, 2002). The permeability begins increasing with depth around $8 \mathrm{~m}$ to another maximum at about $12 \mathrm{~m}$; however, this second maximum is of much smaller amplitude than maxima usually seen around $2 \mathrm{~m}$. This is a new 
observation, unlike previously published permeability profiles. To understand this profile, we turn to measurements of the firn microstructure. The statistics of the microstructure of the 2000-1 core show sudden, corresponding changes at $8 \mathrm{~m}$. Figure 3 shows that the mean grain-size and mean pore size exhibit marked increases, while the specific surface decreases suddenly at $8 \mathrm{~m}$. The images in Figure 4 show the visual evidence of these changes. Each of the images represents fine-grained layers of the core. The image from $12.87 \mathrm{~m}$ depth is very near the second maximum in permeability, and we can see larger, more open pores in this image compared to the surrounding firn images. This more open network of pores in the $12.87 \mathrm{~m}$ image contributes to the increased permeability in that firn.

These differences in microstructure are likely due to differences in the conditions present when this snow was deposited. As discussed above, the stronger temperature gradients in the top meter of firn, resulting from diurnal and seasonal weather patterns, can cause much more rapid grain growth than can the weaker temperature gradients that exist below the top several meters (Rick and Albert, 2004). In addition, ventilation has its greatest impact on interstitial transport in the top several meters (Albert and Shultz, 2002). Thus, the different microstructure that currently exists around $12 \mathrm{~m}$ at this site is most likely due to changing local climatic conditions between the time that these layers were deposited and the time the core was retrieved.

There are multiple climatic conditions that could have caused a difference in the microstructure at this site compared to the permeability profiles at other sites. We explore several possibilities in this paper. One is that the mid-1980s experienced lower accumulation rates than at the present time. This would allow snow to remain in the near-surface region of strong temperature gradients for a longer period of time. As discussed above, strong temperature gradients result in more rapid grain growth and increased permeability.

A second explanation, assuming that the accumulation rate has remained constant, is that the mean annual temperatures could have been higher in the mid-1980s, resulting in more rapid grain growth when the firn that is currently at $12 \mathrm{~m}$ depth was at the surface. The second permeability maximum was accumulation from the 1980s, and the changes beginning at $8 \mathrm{~m}$ in the firn core correspond to an age of approximately 1990. If the local climate was warmer in the 1980s, the snow grains would have been larger, as would the pores, resulting in a higher permeability in the layers deposited in those years.

Another possibility is that decadal or shorter-scale climate variability resulting in several years of higher accumulation in the 1990s caused differences in crystal residence time in the near-surface. A shorter-term, high-accumulation period would result in less metamorphosis and generally lower permeability for layers such as those at approximately $8 \mathrm{~m}$ in this core. This is consistent with the observations of Kaspari and others (2004), who found that the 1992-94 El Niño period resulted in above-mean accumulation for many sites in West Antarctica, including this site.

Clearly, permeability is related to the local climate record. A climate period that is warmer or has lower deposition rates creates larger grains, more interconnected pore space, and higher permeability near the surface. In the absence of melt, because grains continue to grow (although the growth rates slow as the grains become more deeply embedded in the firn), a warmer or lower-accumulation climate leaves its mark as a band of firn with greater permeability and more interconnected pore space. In contrast, a colder or higher-accumulation climate interval leaves a band of lower permeability and more poorly connected pore space. As the firn ages and becomes more deeply buried, the higher-permeability firn may continue to allow gas diffusion down to pore close-off. In contrast, a lower-permeability firn (created by a colder or higheraccumulation climate) that lies above a higher-permeability (warmer or higher-accumulation climate) may greatly reduce gas diffusion above pore close-off.

\section{CONCLUSIONS}

Permeability is controlled by the microstructural characteristics of the firn, and density has a negligible role in determining the ease with which air flows through the firn. The permeability profile gives evidence of changes in shortand long-term climate and accumulation patterns. The second maximum in permeability of the firn at the ITASE 2000-1 site in West Antarctica is likely due to changes in meteorological conditions at that site in the 10-20years before core retrieval. Either lower temperatures in recent years, higher accumulation rates now than in the past, or a short period of increased accumulation approximately 10 years ago could cause differences in crystal growth rate, which in turn could cause the changes in microstructure and permeability evidenced in this core.

The data presented in this paper show that the climate in the years immediately following deposition creates the subsequent profile of permeability in that firn. These patterns in permeability persist as those layers become buried more deeply in the firn. The variations in permeability profile may affect gas transport as that firn moves deeper, including near pore close-off. Climate shifts may alter the gas record ultimately preserved in an ice core because of the local climate's effect on the permeability profile.

\section{ACKNOWLEDGEMENTS}

We thank D. Meese for useful discussions and for sharing her data on the accumulation rates. We thank P. Mayewski and M. Wumkes for collecting the core, and D. Dixon of the US ITASE field team for doing pit measurements in the field. This research was funded through US National Science Foundation grant NSF-OPP 9814676.

\section{REFERENCES}

Albert, M. R. 1996. Modeling heat, mass, and species transport in polar firn. Ann. Glaciol., 23, 138-143.

Albert, M. R. and R. L. Hawley. 2002. Seasonal changes in snow surface roughness characteristics at Summit, Greenland: implications for snow and firn ventilation. Ann. Glaciol., 35, 510-514.

Albert, M. R. and E. Shultz. 2002. Snow and firn properties and airsnow transport processes at Summit, Greenland. Atmos. Environ., 36(15-16), 2789-2797.

Albert, M. R., E. M. Arons and R.E. Davis. 1996. Firn properties affecting gas exchange at Summit, Greenland: ventilation possibilities. In Wolff, E.W. and R.C. Bales, eds. Chemical exchange between the atmosphere and polar snow. Berlin, etc., Springer-Verlag, 561-565. (NATO ASI Series I: Global Environmental Change 43.) 
Albert, M. R., E. F. Shultz and F. E. Perron, Jr. 2000. Snow and firn permeability at Siple Dome, Antarctica. Ann. Glaciol., 31, 353-356.

Albert, M. R., A. M. Grannas, J. Bottenheim and P. Shepson. 2002. Processes and properties of snow-air transfer in the high Arctic with application to interstitial ozone at Alert, Canada. Atmos. Environ., 36(15-16), 2779-2787.

Alley, R. B. 1988. Concerning the deposition and diagenesis of strata in polar firn. J. Glaciol., 34(118), 283-290.

Clarke, G. K. C. and E. D. Waddington. 1991. A three-dimensional theory of wind pumping. J. Glaciol., 37(125), 89-96.

Colbeck, S.C. 1983. Theory of metamorphism of dry snow. J. Geophys. Res., 88(C9), 5475-5482.

Colbeck, S. C. 1989. Air movement in snow due to windpumping. J. Glaciol., 35(120), 209-213.

Cunningham, J. and E.D. Waddington. 1993. Air flow and dry deposition of non-sea salt sulfate in polar firn: paleoclimatic implications. Atmos. Environ., 27A(17-18), 2943-2956.

Gjessing, Y.T. 1977. The filtering effect of snow. International
Association of Hydrological Sciences Publication 118 (Symposium at Grenoble 1975 - Isotopes and Impurities in Snow and Ice), 199-203.

Gow, A.J. 1969. On the rates of growth of grains and crystals in South Polar firn. J. Glaciol., 8(53), 241-252.

Kaspari, S. and 6 others. 2004. Climate variability in West Antarctica derived from annual accumulation rate records from ITASE firn/ice cores. Ann. Glaciol., 39 (see paper this volume). Luciano, G. L. and M. R. Albert. 2002. Bidirectional permeability measurements of polar firn. Ann. Glaciol., 35, 63-66.

Morse, D. L., D. D. Blankenship, E. D. Waddington and T. A. Neumann. 2002. A site for deep ice coring in West Antarctica: results from aerogeophysical surveys and thermo-kinematic modeling. Ann. Glaciol., 35, 36-44.

Perla, R. 1982. Preparation of section planes in snow specimens. J. Glaciol., 28(98), 199-204.

Rick, U. K. and M. R. Albert. 2004. Microstructure of West Antarctic firn and its effect on permeability. CRREL Tech Rep. 96. Hanover, $\mathrm{NH}$, Cold Regions Research and Engineering Laboratory. 